\title{
Associations of proactive coping and self-efficacy with psychosocial outcomes in individuals after stroke
}

Citation for published version (APA):

Tielemans, N. S., Schepers, V. P., Visser-Meily, J. M., Post, M. W., \& van Heugten, C. M. (2015).

Associations of proactive coping and self-efficacy with psychosocial outcomes in individuals after stroke. Archives of Physical Medicine and Rehabilitation, 96(8), 1484-1491.

https://doi.org/10.1016/j.apmr.2015.04.009

Document status and date:

Published: 13/05/2015

DOI:

10.1016/j.apmr.2015.04.009

Document Version:

Publisher's PDF, also known as Version of record

Document license:

Taverne

Please check the document version of this publication:

- A submitted manuscript is the version of the article upon submission and before peer-review. There can be important differences between the submitted version and the official published version of record.

People interested in the research are advised to contact the author for the final version of the publication, or visit the DOI to the publisher's website.

- The final author version and the galley proof are versions of the publication after peer review.

- The final published version features the final layout of the paper including the volume, issue and page numbers.

Link to publication

\footnotetext{
General rights rights.

- You may freely distribute the URL identifying the publication in the public portal. please follow below link for the End User Agreement:

www.umlib.nl/taverne-license

Take down policy

If you believe that this document breaches copyright please contact us at:

repository@maastrichtuniversity.nl

providing details and we will investigate your claim.
}

Copyright and moral rights for the publications made accessible in the public portal are retained by the authors and/or other copyright owners and it is a condition of accessing publications that users recognise and abide by the legal requirements associated with these

- Users may download and print one copy of any publication from the public portal for the purpose of private study or research.

- You may not further distribute the material or use it for any profit-making activity or commercial gain

If the publication is distributed under the terms of Article $25 \mathrm{fa}$ of the Dutch Copyright Act, indicated by the "Taverne" license above, 


\title{
Associations of Proactive Coping and Self-Efficacy With Psychosocial Outcomes in Individuals After Stroke
}

\author{
Nienke S. Tielemans, PhD, ${ }^{a, b}$ Vera P. Schepers, $\mathrm{PhD}^{\mathrm{b}}$ Johanna M. Visser-Meily, PhD, ${ }^{\mathrm{b}}$ \\ Marcel W. Post, PhD, ${ }^{\mathrm{b}, \mathrm{c}}$ Caroline M. van Heugten, PhD ${ }^{\mathrm{a}, \mathrm{d}}$
}

From the ${ }^{a}$ Department of Psychiatry and Neuropsychology, School for Mental Health and Neuroscience, Maastricht University Medical Centre, Maastricht; ${ }^{b}$ Brain Center Rudolf Magnus and Center of Excellence for Rehabilitation Medicine, University Medical Center Utrecht and De Hoogstraat Rehabilitation, Utrecht; ' Department of Rehabilitation Medicine, Center for Rehabilitation, University of Groningen, University Medical Center Groningen, Groningen; and ${ }^{d}$ Department of Neuropsychology and Psychopharmacology, Faculty of Psychology and Neurosciences, Maastricht University, Maastricht, The Netherlands.

\begin{abstract}
Objective: To examine the associations of proactive coping and self-efficacy with psychosocial outcomes in individuals after stroke.

Design: Cross-sectional study. Regression analyses were performed.

Setting: Outpatient settings of hospitals and rehabilitation centers.

Participants: Individuals after stroke $(\mathrm{N}=112$; mean age $\pm \mathrm{SD}, 57.1 \pm 8.9 \mathrm{y}$; mean time \pm SD since stroke, $18.9 \pm 28.5 \mathrm{mo})$.

Interventions: Not applicable.

Main Outcome Measures: Proactive coping was measured using the Utrecht Proactive Coping Competence scale (UPCC), and self-efficacy was measured using the General Self-Efficacy Scale (GSES). Psychosocial outcomes were measured as (1) participation with the use of the restriction and satisfaction subscales of the Utrecht Scale for Evaluation of Rehabilitation-Participation (USER-Participation); (2) emotional problems with the use of the Hospital Anxiety and Depression Scale (HADS); (3) life satisfaction with the use of 2 questions (2LS); and (4) health-related quality of life (HRQOL) with the use of the Short Stroke-Specific Quality of Life scale (SS-QOL-12).

Results: Higher UPCC scores were associated with lower HADS scores $(\beta=-.55, P<.001)$ and with higher USER-Participation satisfaction ( $\beta=.31, P=.001)$, 2LS $(\beta=.34, P<.001)$, and SS-QOL-12 scores $(\beta=.44, P<.001)$. The influence of UPCC scores on HRQOL was indirect through self-efficacy. Higher GSES scores were associated with higher UPCC scores $(\beta=.65, P<.001)$, which in turn were associated with lower HADS scores $(\beta=-.51, P<.001)$. GSES scores were directly associated with higher SS-QOL-12 scores $(\beta=.32, P=.002)$. GSES scores did not influence the association between UPCC scores and any of the psychosocial outcomes (all $P>.0025$ ).

Conclusions: Proactive coping and self-efficacy have different associations with each of the psychosocial outcomes. Therefore, outcome-specific models appear to be necessary to describe these associations.

Archives of Physical Medicine and Rehabilitation 2015;96:1484-91

(C) 2015 by the American Congress of Rehabilitation Medicine
\end{abstract}

Stroke is a major health problem and has a worldwide incidence of 257.96 per 100,000 persons in $2010 .^{1}$ More individuals in the Western world survive strokes, ${ }^{2}$ and most of them return home after hospitalization. ${ }^{3,4}$ Many of these individuals have to adjust to

Supported by the Dutch VSBFonds (grant no. 89000004) and the Dutch Heart Foundation. Disclosures: none. long-term physical and psychosocial effects. ${ }^{5,6}$ Coping and selfefficacy have been proposed as important determinants of the adaptation process in individuals after stroke.

Folkman et $\mathrm{al}^{8}$ defined coping as "the person's cognitive and behavioral efforts to manage (reduce, minimize, master, or tolerate) the internal and external demands of the personenvironment transaction that is appraised as taxing or exceeding the person's resources." ${ }^{,(p 572)}$ Thus, coping refers both to actively 


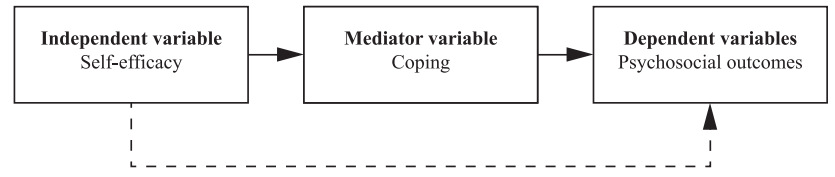

Fig 1 Schematic representation of coping as mediator between self-efficacy and psychosocial outcomes.

changing the situation at hand (ie, problem-based coping) and to regulating the emotions in a situation (ie, emotion-based coping). ${ }^{8}$ Prior research on coping has primarily focused on coping in response to a situation. ${ }^{9}$ Recent research has examined the more future-oriented coping strategy of proactive coping-that is, the efforts adopted to prevent or modify a potential problem situation before it actually arises. ${ }^{9-12}$ Thus, proactive coping is a problembased coping strategy. In individuals after stroke, proactive coping was positively related to health-related quality of life (HRQOL), and this association was stronger compared with other coping strategies and HRQOL. ${ }^{11}$

Self-efficacy is defined as a person's confidence in his/her own competence to successfully accomplish actions. ${ }^{13}$ Higher selfefficacy has been associated with higher HRQOL in individuals after stroke. ${ }^{14,15}$ The relationship between proactive coping and selfefficacy has not been examined in individuals after stroke, but higher levels of other problem-based coping strategies have been associated with higher self-efficacy in people with acquired brain injuries. ${ }^{16}$

Recently, a model has been proposed that describes the role of self-efficacy and more classic coping in psychosocial functioning after acquired brain injury. ${ }^{7}$ According to this model, self-efficacy influences psychosocial outcomes both directly (see the dashed line in fig 1) and indirectly through coping (see the continuous lines in fig 1). It is not known whether this model can be generalized to proactive coping. Additionally, empirical evaluations of this model are lacking, which is problematic because associations of coping and self-efficacy with psychosocial outcomes were found to be different for other chronic conditions from those described in the model by Brands et al. ${ }^{7}$ For example, in individuals with diabetes, self-efficacy influenced (ie, moderated) the association between coping and behavioral outcomes (fig 2).

This study examined the associations of proactive coping and self-efficacy with psychosocial outcomes in individuals after stroke. Because this study is part of the Dutch Restore4Stroke research program, we focused on the psychosocial outcomes of this program. ${ }^{17}$ Therefore, we measured participation restrictions, satisfaction with participation, emotional functioning, life satisfaction, and HRQOL. Based on the previously described model that is specific to acquired brain injury, ${ }^{7}$ we expected that (1) higher proactive coping and self-efficacy would be associated with fewer participation restrictions and higher satisfaction with

$\begin{aligned} & \text { List of abbreviations: } \\ & \text { ADL } \text { activities of daily living } \\ & \text { GSES } \text { General Self-Efficacy Scale } \\ & \text { HADS } \text { Hospital Anxiety and Depression Scale } \\ & \text { HRQOL } \text { health-related quality of life } \\ & 2 \text { LS } 2 \text { life satisfaction questions } \\ & \text { SS-QOL-12 } \text { Short Stroke-Specific Quality of Life scale } \\ & \text { UPCC } \text { Utrecht Proactive Coping Competence scale } \\ & \text { USER-Participation } \text { Utrecht Scale for Evaluation of } \\ & \text { Rehabilitation-Participation }\end{aligned}$

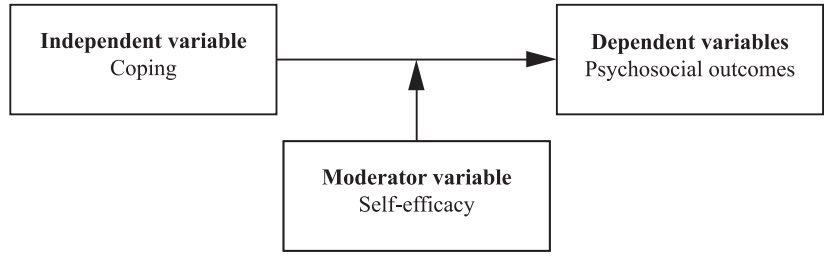

Fig 2 Schematic representation of self-efficacy as moderator between coping and psychosocial outcomces

participation, emotional functioning, life satisfaction, and HRQOL; (2) the influence of self-efficacy on these outcomes would be both direct and indirect (ie, mediated through proactive coping); and (3) self-efficacy would not moderate the associations between proactive coping and psychosocial outcomes.

\section{Methods}

\section{Design}

This cross-sectional study examined the baseline data of individuals after stroke who participated in the Restore4Stroke Self-Management study. It is a randomized controlled trial examining the effectiveness of a self-management intervention that is aimed at teaching individuals after stroke and partners proactive coping strategies in comparison to an educational program. The overall study design is published elsewhere. ${ }^{18}$ The study was approved by the Medical Ethics Committee of the University Medical Center Utrecht and the ethics committees of the participating institutions.

\section{Participants}

Inclusion criteria were (1) having had a first or recurrent symptomatic stroke (ischemic or intracerebral hemorrhage) $\geq 6$ weeks before recruitment; (2) living at home; (3) being $\geq 18$ years of age; and (4) having participation problems as indicated by $\geq 2$ items of the restriction subscale of the Utrecht Scale for Evaluation of Rehabilitation-Participation (USER-Participation). ${ }^{19}$ Exclusion criteria were (1) inadequate mental ability to understand or benefit from the intervention; (2) behavioral problems interfering with adequate group functioning; (3) inadequate Dutch language skills (score $<5$ on the shortened version of the Aphasia Scale of the Dutch Aphasia Foundation) $)^{20}$; (4) having major depression and/or (5) participating in a psychological treatment program of proactive coping at the time of recruitment. A rehabilitation physician or nurse practitioner clinically judged these criteria. ${ }^{18}$

\section{Procedures}

Between February 2012 and May 2013, rehabilitation physicians and nurse practitioners selected individuals after stroke for the Restore4Stroke Self-Management study, through case finding at 8 Dutch rehabilitation centers and hospitals. Eligible individuals were informed about the study during their regular outpatient consultations, and interested individuals received an information letter about the study. After 5 days, the researcher asked these individuals if they wanted to participate. On giving consent, they were placed on a waiting list until enough individuals $(n=8)$ were 
recruited for the parallel provision of the group-based self-management intervention and group-based educational intervention in 1 center. Once 8 individuals were recruited, the researcher made individual appointments to obtain baseline measurements for each participant. After signing informed consent, the participant completed the questionnaires on paper during the baseline appointment. The baseline measurements took place at the participant's home or medical center based on his/her preference. The researcher or research assistant was present at all baseline measurements.

\section{Measures}

\section{Independent variables}

Proactive coping was measured using the Utrecht Proactive Coping Competence scale (UPCC). This self-assessment scale consists of 21 items assessed on a 4-point scale ranging from "not competent at all" to "very competent." Averaging all the item scores results in the total score (range, 1-4). Higher scores represent higher proactive coping. The UPCC demonstrated good psychometric properties in individuals after stroke. ${ }^{11}$

Self-efficacy was measured using the Dutch version of the General Self-Efficacy Scale (GSES). This self-assessment consists of 10 items assessed on a 4-point scale ranging from "not at all true" to "exactly true." Adding all the item scores together results in the total score (range, 10-40). Higher scores represent higher self-efficacy. The GSES demonstrated good psychometric properties in the Dutch population. ${ }^{21}$

\section{Outcome variables}

The psychosocial outcomes assessed in this study were participation restrictions and satisfaction, emotional functioning, life satisfaction, and HRQOL.

Participation was measured using both the restriction and satisfaction subscales of the USER-Participation. The 11 items of the USER-Participation restriction subscale are assessed on a 3point scale ranging from "not possible at all" to "effortless." The 11 items of the USER-Participation satisfaction subscale are assessed on a 5-point scale ranging from "not satisfied at all" to "very satisfied." Participants can indicate that an item is irrelevant for them, using a "not applicable" option. Total scores are calculated for both subscales separately by adding the item scores together and converting the resulting sum into scores on a 0-to100 scale. Higher scores represent higher participation, which indicates fewer participation restrictions or higher participation satisfaction. Both subscales demonstrated good psychometric properties in former and current outpatient rehabilitation participants. ${ }^{19,22}$

Emotional functioning was measured using the total scale of the Dutch version of the Hospital Anxiety and Depression Scale (HADS). Adding together 7 item scores measuring depressive symptoms and 7 item scores measuring anxiety symptoms results in the total score of this self-assessment (range, 0-42). Higher scores represent more intense emotional problems. The HADS has demonstrated good psychometric properties in individuals after stroke and several other Dutch populations. ${ }^{23,24}$

Life satisfaction was measured using 2 life satisfaction questions (2LS). One question assessed life satisfaction at the time of the evaluation, on a 6-point scale ranging from "very unsatisfactory" to "very satisfactory." The other question assessed current life satisfaction compared with life satisfaction before the stroke on a 7-point scale ranging from "much worse" to "much better." Adding the 2 question scores results in the total score (range, 2-13). Higher scores represent higher life satisfaction. The 2LS demonstrated sufficient psychometric properties in the neurologic population of individuals with spinal cord injuries. ${ }^{25}$

HRQOL was measured using the Dutch version of the Short Stroke-Specific Quality of Life scale (SS-QOL-12). This selfassessment consists of 12 items, with 6 items measured on a 5point scale ranging from "could not do it at all" to "no trouble at all," and 6 items measured on a 5-point scale ranging from "strongly agree" to "strongly disagree." Adding the item scores resulted in the total score (range, 12-60). Higher scores represent higher levels of HRQOL. The SS-QOL-12 has demonstrated good psychometric populations in individuals after stroke. ${ }^{26}$

\section{Confounders}

Potential confounders considered included the demographic characteristics of age, sex, and marital status (cohabiting with a partner or not); stroke characteristics including time since the stroke in months and stroke history (first stroke/multiple strokes); and dependency in activities of daily living (ADL) (no/yes) and cognitive impairment (no/yes). ADL was measured using the Barthel Index (0-20), with dependency in ADL denoted for Barthel Index scores $<18 .{ }^{27}$ Cognitive functioning was measured using the Montreal Cognitive Assessment, with impaired cognitive functioning denoted by Montreal Cognitive Assessment scores $<26$. $^{28}$

\section{Sample size}

We did not perform a formal sample size calculation. Rather, the number of participants in the Restore4Stroke Self-Management study determined the sample size.

\section{Statistical analysis}

Associations between UPCC and GSES scores and associations of the UPCC and GSES scores with the dependent variables (USERParticipation restrictions, USER-Participation satisfaction, HADS, 2LS, and SS-QOL-12 scores) were described. Correlations $<0.3$ indicated a weak association, those between 0.3 and 0.6 indicated a moderate association, and correlations $>0.6$ indicated a strong association. $^{29}$

The assumptions checked in the linear regression analysis included linearity, homoscedasticity, independence, normality, multicollinearity between dependent and independent variables $(r>.80)$, and influential outliers (Cook's distance $>1$ ).

Direct associations between UPCC and GSES scores (independent variables) and each psychosocial outcome (dependent variables, ie, USER-Participation restrictions and satisfaction, HADS, 2LS, and SS-QOL-12 scores) were examined using simple regression analyses.

Then, the indirect effect of self-efficacy on each psychosocial outcome through proactive coping was investigated-that is, whether the effect of self-efficacy was mediated through proactive coping. We followed the method of Baron and Kenny ${ }^{30}$ for this. The simple regression analyses described above were the first 2 steps in this process. In step 3, we examined whether GSES scores had a direct effect on UPCC scores by using a simple regression analysis. In step 4, we examined whether GSES scores had 
Table 1 Participant characteristics $(\mathrm{N}=112)$

\begin{tabular}{lc}
\hline Characteristics & Values \\
\hline Demographic & \\
Sex: male & $59(52.7)$ \\
Age (y) & $57.1 \pm 8.9$ \\
Educational level: high ${ }^{*, \dagger}$ & $36(32.1)$ \\
Marital status: living with partner & $81(72.3)$ \\
Employment status: employed after stroke & $25(22.3)$ \\
Stroke & \\
Time after stroke (mo) & $18.9 \pm 28.5$ \\
Stroke history: $>1$ stroke & $18(16.1)$ \\
Dependence in ADL: individuals & $20(17.9)$ \\
$\quad$ with BI $<18^{\S}$ & \\
Cognitive impairment: individuals & $66(58.9)$ \\
$\quad$ with MoCA $<26^{\S}$ & \\
Communication impairment: individuals & $53(47.3)$ \\
$\quad$ with SAN $<7$ & \\
Measures & \\
UPCC (1-4) & \\
GSES (1-40) & $2.9 \pm 0.5$ \\
USER-Participation restrictions (0-100) & \\
USER-Participation satisfaction (0-100) & \\
HADS total $(0-42) \|$ & $72.1 \pm 16.0$ \\
2LS (1-13) & $60.8 \pm 17.1$ \\
SS-Q0L-12 total (1-5) & $13.1 \pm 6.9$ \\
\hline
\end{tabular}

NOTE. Values are $n(\%)$ or mean \pm SD.

Abbreviations: BI, Barthel Index; MoCA, Montreal Cognitive Assessment; SAN, shortened version of the Aphasia Scale of the Dutch Aphasia Foundation; USER-Participation restrictions, restriction subscale of the USER-Participation; USER-Participation satisfaction, satisfaction subscale of the USER-Participation.

* Higher professional education or university degree.

$\mathrm{n}=109$.

$\ddagger \mathrm{n}=108$.

$\S \mathrm{n}=111$.

II Higher scores indicate higher levels of the measured construct.

ฯ Higher scores indicate lower levels of the measured construct.

additional predictive value over UPCC scores for each psychosocial outcome by using multiple regression analyses. ${ }^{30}$

Finally, we examined whether associations between UPCC scores and each psychosocial outcome measure were influenced (moderated) by GSES scores. Multiple regression analyses were performed; the UPCC and GSES scores and the interaction term GSES $\times$ UPCC were added to the model as independent variables. A significant interaction between UPCC and GSES scores would indicate moderation.
Demographic characteristics, stroke characteristics, dependence in ADL, and cognitive impairment were entered as confounders in the model if their addition caused a change of $>10 \%$ in the B-values of the main effect or interaction. If there were multiple confounders, they were added to the model in a stepwise manner, with the strongest confounders added first. This process terminated once B-values did not change by $>10 \%$. $^{31}$

Data were analyzed using IBM SPSS Statistics 21.0. ${ }^{\text {a }}$ Correlations were considered as statistically significant if $P<.05$. For regression analyses, $P<.0025$ was considered statistically significant, based on the Bonferroni correction for multiple testing. Continuous variables and confounders were centered to their means. Listwise deletion was used when data were missing for 1 of the questionnaires inventorying either of the independent variables, UPCC or GSES scores, or an outcome variable (ie, USER-Participation restriction or satisfaction, HADS, 2LS, and SS-QOL-12 scores). Pairwise deletion was used for missing confounder data.

\section{Results}

\section{Participants}

Of 167 individuals after stroke who were invited to participate in the Restore4Stroke Self-Management study, 113 consented. One individual did not complete the questionnaires, so this study was based on the data from 112 individuals. Table 1 displays the participants' characteristics.

\section{Correlations}

Table 2 displays correlations of UPCC and GSES scores with each psychosocial outcome. Moderate positive associations were found for UPCC scores with USER-Participation satisfaction $(r=.34$, $P<.001), 2 \mathrm{LS}(r=.36, P<.001)$, and SS-QOL-12 scores $(r=.38$, $P<.001$ ), indicating that higher UPCC scores are associated with higher scores on the USER-Participation satisfaction, 2LS, and SS-QOL-12 assessments. A moderate negative association was found between UPCC and HADS scores $(r=-.54, P<.001)$, indicating that higher UPCC scores are associated with lower HADS scores.

A strong positive association was found between GSES and UPCC scores $(r=.67, P<.001)$, indicating that higher GSES scores are associated with higher UPCC scores. A weak positive association was found between GSES and USER-Participation satisfaction scores $(r=.23, P=.013)$, indicating that higher GSES scores are associated with higher USER-Participation satisfaction scores. Moderate positive associations were found

Table 2 Associations between proactive coping, self-efficacy, and psychosocial outcomes

\begin{tabular}{lccccc}
\hline Measures & USER-Participation Restrictions & USER-Participation Satisfaction & HADS Total & 2LS & SS-Q0L-12 Total \\
\hline UPCC & .05 & $.34^{*}$ & $-.54^{*}$ & $.36^{*}$ & $.38^{*}$ \\
GSES & .10 & $.23^{\dagger}$ & $-.53^{*}$ & $.35^{*}$ & $.41^{*}$ \\
\hline
\end{tabular}

NOTE. $r$ UPCC, GSES $=.67 ; P<.001$.

Abbreviations: USER-Participation Restrictions, restriction subscale of the USER-Participation; USER-Participation Satisfaction, satisfaction subscale of the USER-Participation.

${ }^{*} P<.001 ;{ }^{\dagger} P<.05$ was considered statistically significant. 
between GSES and 2LS scores $(r=.35, P<.001)$, and GSES and SS-QOL-1 2 scores $(r=.41, P<.001)$, indicating that higher GSES scores are associated with higher scores on the 2LS and SS-QOL12 assessments. A moderate negative association was found between GSES and HADS scores $(r=-.53, P<.001)$, indicating that higher GSES scores are associated with lower HADS scores.

\section{Regression analyses}

Table 3 presents the 4-step approach of Baron and Kenny ${ }^{30}$ for testing mediation.

Step 1 assesses whether UPCC scores were directly associated with psychosocial outcomes. Higher UPCC scores were associated with lower HADS scores $(\beta=-.55, P<.001)$ and higher scores on the USER-Participation satisfaction $(\beta=.31, P=.001), 2 \mathrm{LS}$ $(\beta=.34, P<.001)$, and SS-QOL-12 $(\beta=.44, P<.001)$ assessments.

Step 2 assesses whether GSES scores were directly associated with psychosocial outcomes. Higher GSES scores were associated with lower HADS scores $(\beta=-.51, P<.001)$ and higher scores on the 2LS $(\beta=.34, P<.001)$ and SS-QOL-12 $(\beta=.47, P<.001)$ assessments.

Step 3 assesses whether GSES scores were directly associated with UPCC scores. Higher GSES scores were associated with higher UPCC scores $(\beta=.65, P<.001)$.

Step 4 assesses whether GSES scores had additional predictive value over UPCC scores for each psychosocial outcome. GSES scores had an indirect influence through proactive coping on HADS scores $(P>$.0025) and a direct effect on SS-QOL-12 scores $(\beta=.32, P=.002)$. UPCC scores had an indirect influence through self-efficacy on SS-QOL-12 scores $(P>.0025)$.

No significant UPCC $\times$ GSES interactions were found in any model $(P>.05)$. Thus, the associations between the UPCC scores and each psychosocial outcome measure were not moderated by GSES scores.

\section{Discussion}

Proactive coping and self-efficacy were differently associated with various psychosocial outcomes in individuals after stroke. Proactive coping was associated with all of the psychosocial outcomes, except for participation restrictions. However, the association between proactive coping and HRQOL was mediated by selfefficacy and was thus indirect. Self-efficacy was associated with emotional functioning, life satisfaction, and HRQOL. However, proactive coping fully mediated the association between selfefficacy and emotional functioning; therefore, these associations were also indirect. Self-efficacy did not influence the association between proactive coping and the psychosocial outcome measures, so no moderation effects of self-efficacy on these associations were observed.

The absence of an association between proactive coping and participation restrictions has also been reported for individuals with chronic obstructive pulmonary disease. ${ }^{32}$ This finding was not consistent with conceptualizing proactive coping as a problem-based coping strategy because such strategies are expected to foster individuals' capacities to actively change a situation. Further research is needed to clarify this unexpected result and to elucidate different coping strategies in individuals with chronic conditions. Nevertheless, it appears that increasing proactive coping strategies is insufficient for reducing participation restrictions in individuals after stroke.
Our finding that self-efficacy was not associated with participation restrictions and satisfaction deviated from findings in individuals with spinal cord injury. ${ }^{33}$ Factors other than self-efficacy could have determined participation in individuals after stroke. For example, spinal cord injuries often result in visible physical impairments, such as reduced leg function. ${ }^{34}$ In contrast, individuals after stroke are often confronted with behavioral, cognitive, and emotional effects, which are largely invisible. ${ }^{35-38}$ Consequently, the capacities of individuals after stroke are easily overestimated by relatives and people in the community, resulting in unrealistic expectations about the participation levels of individuals after stroke. ${ }^{39,40}$ Therefore, social pressure might determine these participation levels more strongly than selfefficacy. Thus, to increase participation levels in individuals after stroke, it might be better to focus on factors other than selfefficacy. Theoretically, it is important to recognize that the results observed for predominantly physical chronic conditions such as spinal cord injury do not automatically generalize to conditions such as stroke. Thus, disease-specific models are needed to describe psychosocial functioning, for individuals after stroke.

The strong association between proactive coping and selfefficacy was only problematic when investigating their separate associations with life satisfaction. Self-efficacy was indirectly associated with emotional functioning through proactive coping. Unexpectedly, proactive coping was indirectly associated with HRQOL through self-efficacy. Thus, different theoretical models are needed to describe the various psychosocial outcomes in individuals after stroke. Clinically, interventions aimed at improving emotional functioning in individuals after stroke might be more effective when focusing on increasing proactive coping, because this construct is more closely related to this psychosocial outcome. In contrast, self-efficacy might be a better target for improving HRQOL. Further research is needed to verify this assumption of distinct therapeutic approaches for improving various aspects of psychosocial functioning.

\section{Study limitations}

The causal nature of the associations could not be determined because of the cross-sectional study design. Although cognitive and communicative impairments could have reduced the validity of the self-assessment questionnaires, this effect was considered acceptable because individuals with severe impairments in these areas were excluded beforehand by their rehabilitation physicians or nurse practitioners. The generalizability of the results might be limited because the individuals selected for the study sample had sustained relatively mild strokes. Compared with unpublished data from individuals in the Restore4Stroke Cohort study who were living at home 1 year after their strokes, our sample included more women, younger subjects, and subjects who were more frequently independent in ADL. ${ }^{17}$

\section{Conclusions}

Proactive coping and self-efficacy have different associations with each of the psychosocial outcomes. Therefore, disease-specific models should be developed, but also different models are needed for various psychosocial outcomes. Further investigation, including structural equation modeling, appears necessary for a better understanding of how psychosocial outcomes can be influenced in individuals after stroke. 
Table 3 Regression analyses of the associations between proactive coping and self-efficacy with psychosocial outcomes

\begin{tabular}{|c|c|c|c|c|c|c|c|c|c|c|c|c|c|c|c|c|c|c|c|}
\hline \multirow[b]{3}{*}{ Steps } & \multirow{3}{*}{$\begin{array}{l}\text { Independent } \\
\text { Variables }\end{array}$} & \multicolumn{15}{|c|}{ Psychosocial Outcomes } & \multicolumn{3}{|c|}{ Independent Variable } \\
\hline & & \multicolumn{3}{|c|}{$\begin{array}{l}\text { USER-Participation } \\
\text { Restriction }\end{array}$} & \multicolumn{3}{|c|}{$\begin{array}{l}\text { USER-Participation } \\
\text { Satisfaction }\end{array}$} & \multicolumn{3}{|c|}{ HADS } & \multicolumn{3}{|c|}{$2 \mathrm{LS}$} & \multicolumn{3}{|c|}{ SS-Q0L-12 } & \multicolumn{3}{|c|}{ UPCC } \\
\hline & & $\beta$ & $t$ & $P$ & $\beta$ & $t$ & $P$ & $\beta$ & $t$ & $P$ & $\beta$ & $t$ & $P$ & $\beta$ & $t$ & $P$ & $\beta$ & $t$ & $P$ \\
\hline 1 & UPCC & $.05^{*}$ & .50 & .615 & .31 & 3.47 & $.001^{\dagger}$ & -.55 & -6.93 & $<.001^{\dagger}$ & .34 & 3.76 & $<.001^{\dagger}$ & $.44^{\ddagger}$ & 5.50 & $<.001^{\dagger}$ & & & \\
\hline 2 & GSES & $.16^{\S}$ & 1.74 & .085 & $.18^{\|}$ & 1.94 & .055 & -.51 & -6.25 & $<.001^{\dagger}$ & $.34^{\pi}$ & 3.83 & $<.001^{\dagger}$ & $.47^{\#}$ & 5.94 & $<.001^{\dagger}$ & & & \\
\hline 3 & GSES & & & & & & & & & & & & & & & & .65 & 8.88 & $<.001^{*}$ \\
\hline \multirow[t]{2}{*}{4} & UPCC & $-.06^{* *}$ & -.55 & .583 & $.32^{\dagger \dagger}$ & 2.70 & .008 & -.38 & -3.73 & $<.001^{\dagger}$ & $.24^{+\ddagger}$ & 2.15 & .034 & $.24^{\S \S}$ & 2.46 & .016 & & & \\
\hline & GSES & $.20^{* *}$ & 1.69 & .094 & $-.03^{\dagger \dagger}$ & -.21 & .832 & -.27 & -2.63 & .010 & $.19^{+}$ & 1.68 & .096 & $.32^{\S \S}$ & 3.18 & $.002^{\dagger}$ & & & \\
\hline
\end{tabular}

NOTE. The steps in the first column represent the 4 steps of the method of Baron and Kenny, ${ }^{30}$ with step 1 examining the direct associations between UPCC scores and the psychosocial outcomes, step 2 examining the direct associations between GSES scores and the psychosocial outcomes, step 3 examining the direct association between UPCC and GSES scores, and step 4 examining whether GSES scores had an additional predictive value over UPCC scores for each of the psychosocial outcome measures.

Abbreviations: USER-Participation Restrictions, restriction subscale of the USER-Participation; USER-Participation Satisfaction, satisfaction subscale of the USER-Participation.

The following confounders were added to the model:

* Dependent in $\operatorname{ADL}(\beta=-.44, P<.001)$; cognitively impaired $(\beta=-.09, P=.352)$; had $>1$ stroke $(\beta=.14, P=.143)$; age $(\beta=.10, P=.303)$.

$\uparrow<<.0025$ was considered statistically significant.

Dependent in ADL $(\beta=-.41, P<.001)$.

Dependent in $\operatorname{ADL}(\beta=-.45, P<.001)$; time since stroke $(\beta=.10, P=.284)$

Age $(\beta=.20, P=.034)$.

Dependent in $\mathrm{ADL}(\beta=-.22, P=.014)$.

\# Dependent in $\operatorname{ADL}(\beta=-.41, P<.001)$.

** Dependent in $\operatorname{ADL}(\beta=-.45, P<.001)$; time since stroke $(\beta=.10, P=.275)$.

it Age $(\beta=.21, P=.024)$.

Dependent in ADL $(\beta=-.23, P=.009)$

Dependent in $\operatorname{ADL}(\beta=-.42, P<.001)$. 


\section{Supplier}

a. IBM SPSS Statistics 21.0; IBM Corp.

\section{Keywords}

Coping behavior; Quality of life; Rehabilitation; Self efficacy; Stroke

\section{Corresponding author}

Caroline M. van Heugten, PhD, Maastricht University, Department of Psychiatry and Neuropsychology, Faculty of Health, Medicine and Life Sciences, PO Box 616, 6200 MD Maastricht, The Netherlands. E-mail address: c.vanheugten@ maastrichtuniversity.nl.

\section{Acknowledgments}

We thank Wendy van Veen, MSc, for her valuable contribution to the design of the study.

\section{References}

1. Feigin VL, Forouzanfar MH, Krishnamurthi R, et al. Global and regional burden of stroke during 1990-2010: findings from the Global Burden of Disease Study 2010. Lancet 2014;383:245-55.

2. Vaartjes I, O'Flaherty M, Capewell S, Kappelle J, Bots M. Remarkable decline in ischemic stroke mortality is not matched by changes in incidence. Stroke 2013;44:591-7.

3. Vaartjes I, Reitsma JB, de Bruin A, et al. Nationwide incidence of first stroke and TIA in the Netherlands. Eur J Neurol 2008;15:1315-23.

4. Van Exel NJ, Koopmanschap MA, Scholte op Reimer W, Niessen LW, Huijsman R. Cost-effectiveness of integrated stroke services. QJM 2005;98:415-25.

5. Mayo NE, Wood-Dauphinee S, Carlton R, Durcan L, Carlton J. Activity, participation, and quality of life 6 months poststroke. Arch Phys Med Rehabil 2002;83:1035-42.

6. Godwin KM, Ostwald SK, Cron SG, Wasserman J. Long-term healthrelated quality of life of stroke survivors and their spousal caregivers. J Neurosci Nurs 2013;45:147-54.

7. Brands IM, Wade DT, Stapert SZ, van Heugten CM. The adaptation process following acute onset disability: an interactive twodimensional approach applied to acquired brain injury. Clin Rehabil 2012;26:840-52.

8. Folkman S, Lazarus R, Gruen R, DeLongis A. Appraisal, coping, health status, and psychological symptoms. J Pers Soc Psychol 1986;3: 571-9.

9. Aspinwall LG, Taylor SE. A stitch in time: self-regulation and proactive coping. Psychol Bull 1997;121:417-36.

10. Bode C, de Ridder DT, Kuijer RG, Bensing JM. Effects of an intervention promoting proactive coping competencies in middle and late adulthood. Gerontologist 2007;47:42-51.

11. Tielemans NS, Visser-Meily JM, Schepers VP, Post MW, van Heugten CM. Proactive coping poststroke: psychometric properties of the Utrecht Proactive Coping Competence Scale. Arch Phys Med Rehabil 2014:95:670-5.

12. Thoolen BJ, de Ridder D, Bensing J, Gorter K, Rutten G. Beyond good intentions: the role of proactive coping in achieving sustained behavioural change in the context of diabetes management. Psychol Health 2009;24:237-54.
13. Bandura A. Self-efficacy: toward a unifying theory of behavioral change. Psychol Rev 1977;84:191-215.

14. LeBrasseur NK, Sayers SP, Ouellette MM, Fielding RA. Muscle impairments and behavioral factors mediate functional limitations and disability following stroke. Phys Ther 2006;86:1342-50.

15. Robinson-Smith G, Johnston MV, Allen J. Self-care self-efficacy, quality of life, and depression after stroke. Arch Phys Med Rehabil 2000;81:460-4.

16. Brands IM, Köhler S, Stapert S, Wade D, van Heugten C. How flexible is coping after acquired brain injury? A 1-year prospective study investigating coping patterns and influence of self-efficacy, executive functioning and self-awareness. J Rehabil Med 2014;46: $869-75$.

17. Van Mierlo ML, van Heugten CM, Post MW, Lindeman E, de Kort PL, Visser-Meily JM. A longitudinal cohort study on quality of life in stroke patients and their partners: Restore4Stroke Cohort. Int J Stroke 2014;9:148-54.

18. Tielemans NS, Visser-Meily JM, Schepers VP, Post MW, Wade DT, van Heugten CM. Study protocol of the Restore4Stroke self-management study: a multicenter randomized controlled trial in stroke patients and their partners. Int J Stroke 2014;9:818-23.

19. Post MW, van der Zee CH, Hennink J, Schafrat CG, Visser-Meily JM, van Berlekom SB. Validity of the Utrecht Scale for Evaluation of Rehabilitation-Participation. Disabil Rehabil 2012;34:478-85.

20. Visser-Meily A, Meijer R. [Discharge guide: decision tree for discharge destination from hospital for patients after stroke] [Dutch]. Hilversum: Mewadruk; 2010.

21. Scholz U, Dona BG, Sud S, Schwarzer R. Is general self-efficacy a universal construct? Eur J Psychol Assess 2002;18:242-51.

22. Van der Zee CH, Kap A, Rambaran Mishre R, Schouten EJ, Post MW. Responsiveness of four participation measures to changes during and after outpatient rehabilitation. J Rehabil Med 2011;43:1003-9.

23. Sagen U, Vik TG, Moum T, Mørland T, Finset A, Dammen T. Screening for anxiety and depression after stroke: comparison of the Hospital Anxiety and Depression Scale and the Montgomery and Asberg Depression Rating Scale. J Psychosom Res 2009;67:325-32.

24. Spinhoven PH, Ormel J, Sloekers PP, Kempen GI, Speckens AE, Van Hemert AM. A validation study of the Hospital Anxiety and Depression Scale (HADS) in different groups of Dutch subjects. Psychol Med 1997;27:363-70.

25. Post MW, van Leeuwen CM, van Koppenhagen CF, de Groot S. Validity of the Life Satisfaction questions, the Life Satisfaction Questionnaire, and the Satisfaction With Life Scale in persons with spinal cord injury. Arch Phys Med Rehabil 2012;93:1832-7.

26. Post MW, Boosman H, van Zandvoort MM, Passier PE, Rinkel GJ, Visser-Meily JM. Development and validation of a short version of the Stroke Specific Quality of Life Scale. J Neurol Neurosurg Psychiatry 2011;82:283-6.

27. Collin C, Wade DT, Davies S, Horne V. The Barthel ADL Index: a reliability study. Int Disabil Stud 1988;10:61-3.

28. Nasreddine ZS, Phillips NA, Bédirian V, et al. The Montreal Cognitive Assessment, MoCA: a brief screening. J Am Geriatr Soc 2005;53: 695-9.

29. Visser-Meily JM, Post MW, Riphagen II, Lindeman E. Measures used to assess burden among caregivers of stroke patients: a review. Clin Rehabil 2004;18:601-23.

30. Baron RM, Kenny DA. The moderator-mediator variable distinction in social psychological research: conceptual, strategic, and statistical considerations. J Pers Soc Psychol 1986;51:1173-82.

31. Van Leeuwen CM, Post MW, van Asbeck FW, et al. Life satisfaction in people with spinal cord injury during the first five years after discharge from inpatient rehabilitation. Disabil Rehabil 2012;34: 76-83.

32. Weldam SW, Lammers JW, Decates RL, Schuurmans MJ. Daily activities and health-related quality of life in patients with chronic obstructive pulmonary disease: psychological determinants: a crosssectional study. Health Qual Life Outcomes 2013;11:190. 
33. Peter C, Müller R, Post MW, van Leeuwen CM, Werner CS, Geyh S. Psychological resources, appraisals, and coping and their relationship to participation in spinal cord injury: a path analysis. Arch Phys Med Rehabil 2014:95:1662-71.

34. Van Asbeck F. [Guideline of rehabilitation in spinal cord injury] [Dutch]. Houten: Bohn Stafleu van Loghum; 2007.

35. Broomfield NM, Scoular A, Welsh P, Walters M, Evans JJ. Poststroke anxiety is prevalent at the population level, especially among socially deprived and younger age community stroke survivors. Int J Stroke 2013 [Epub ahead of print].

36. Carlsson GE, Möller A, Blomstrand C. Consequences of mild stroke in persons < 75 years: a 1-year follow-up. Cerebrovasc Dis 2003;16:383-8.
37. Planton M, Peiffer S, Albucher JF, et al. Neuropsychological outcome after a first symptomatic ischaemic stroke with "good recovery". Eur J Neurol 2012;19:212-9.

38. Rush BK, McNeil RB, Gamble DM, et al. Behavioral symptoms in long-term survivors of ischemic stroke. J Stroke Cerebrovasc Dis 2010;19:326-32.

39. Erikson A, Park M, Tham K. Belonging: a qualitative, longitudinal study of what matters for persons after stroke during the one year of rehabilitation. J Rehabil Med 2010;42:831-8.

40. Carlsson G, Möller A, Blomstrand C. A qualitative study of the consequences of "hidden dysfunctions" one year after a mild stroke in persons $<75$ years. Disabil Rehabil 2004;26:1373-80. 